\title{
Psychological factors and psychosocial interventions for cancer related pain
}

\author{
ANDRADA CIUCĂ $\breve{1}^{1}$, ADRIANA BĂBAN ${ }^{1}$ \\ ${ }^{1}$ Department of Psychology, "Babeş-Bolyai” University, Cluj-Napoca, Romania
}

\begin{abstract}
The present paper is aimed at briefly presenting psychological factors involved in cancer related pain and what psychosocial interventions are efficient in reducing it. Cancer related pain is a complex experience and the most integrative and recommended approach is the biopsychosocial model. It has been proved that chronic pain is more strongly related to psychological factors than to treatment or illness related factors. Psychological factors influencing pain experience can be intuitively grouped starting with awareness of pain (i.e., attentional factor), then with evaluation of pain (i.e., cognitive factors) which is leading to feelings (i.e., emotional factors), and behaviours (i.e., coping strategies) regarding pain. Psychosocial interventions (i.e., skill based and education based interventions) have strong evidence that is effective in reducing cancer related pain.
\end{abstract}

Keywords: cancer, pain, psychological factors, pain management.

\section{INTRODUCTION}

\section{CANCER RELATED PAIN}

Pain is a complex experience emerging from the interaction of patients' thoughts, emotions, and behaviours. Pain is the most frequent, feared and burdensome symptom of cancer [1]. Prevalence of pain in patients diagnosed with cancer is $53 \%$ and this number is increased to $59 \%$ during treatment and to $64 \%$ when cancer is advanced/metastatic/ terminal [2]. Occurrence of pain in cancer patients is mostly due to cancer itself (68\%), cancer treatment $(18 \%)$, or other non-cancer health problems $(16 \%)$. Furthermore, the self-reported intensity of pain is moderate to severe for $73 \%$ patients with cancer [3]. Pain is also frequently persistent even for cancer survivors who completed cancer treatment. Pain and functional limitation is reported after various types of cancer: breast cancer, prostate cancer, colorectal cancer, and gynaecological cancer [4].

\section{BIOPSYCHOSOCIAL MODEL OF CANCER RELATED PAIN}

The experience of pain is shaped by a multitude of factors including biological aspects of illness (e.g., site of cancer), psychological (e.g., beliefs about illness, negative mood), and social context (e.g., social support, access to medical care). Biopsychosocial model provides a framework which integrates the somatic dimension with psychological and social context of the patient in order to better understand the experience and treatment of pain. Evidence suggests that chronic pain is more strongly related to psychological factors than to treatment or illness related factors [5]. Also, research shows that social support is associated with intensity of pain [6]. In recent years many literature reviews found psychosocial intervention to be effective in reducing pain associated with cancer. Thus, psychosocial interventions need to be an addition to biological treatment of cancer related pain.

\section{PSYCHOLOGICAL FACTORS IN CANCER RELATED PAIN}

Psychological factors are known to influence the transition from acute to chronic pain. Psychological factors involved in cancer related pain depend on the status of the patient (e.g. at diagnosis and during treatment, cancer survivors, patients with advanced disease or at the end of life) [7]. Psychological factors involved in experience of pain can be grouped starting with awareness of pain (i.e., attention factor), then with evaluation of pain (i.e., cognitive factors) which is leading to feelings (i.e., emotional factors) and behaviours about pain (i.e., coping strategies) [8].

\section{ATTENTIONAL FACTOR}

One of the purposes of pain is to demand attention. Pain is a warning signal and this inter- 
ruption of attention is helpful and adaptive for survival [9]. This is the reason why ignoring pain is difficult. Focusing attention away from the pain can lead to a decrease in pain intensity [10]. Attention bias modification can have a significant positive effect on reducing pain [11]. One exposure to intense acute pain (e.g., acute postoperative pain) leads to changes in the attentional and emotional processing of pain [12].

\section{COGNITIVE FACTORS}

Once attention has been focused on pain, cognitive factors are involved in interpretation of what it means. Chronic pain is influencing brain functions from molecular to system levels leading to disruptions in brain regions critical for cognitive function. Studies on rodents showed that learning and memory, specifically spatial learning, social recognition memory, and working memory are impaired during pain, and morphine administration can restore performance to cognitive tasks. Decisionmaking is also affected in chronic pain populations and this may be due to the fact that certain brain regions (orbitofrontal cortex and basolateral amygdala) are involved in both decision making and pain [13].

Negative interpretation of pain can have a significant influence in how the pain is experienced. Chronic pain patients showed greater bias towards interpretation ambiguous situations as painful, and a higher fear of pain and catastrophizing is associated with erroneous interpretation of pain [14].

Beliefs and attitudes can have an impact on the experience and treatment of pain. Also pain attitudes are playing a central role in pain behaviours [15]. For example, several ideas are influencing the patients' behaviours regarding pain management: (a) the idea that if something hurts, it must be harmful to the body, (b) the idea that if it hurts, the current activity must be stopped, (c) or the idea that resting is the best way to treat pain [16]. Attitudes about pain can be placed on a negative (i.e., the pain is damaging and uncontrollable and indicates disability) or positive (i.e., pain is manageable) continuum [17]. Negative attitudes regarding pain have been associated with poor psychological functioning and physical activity levels [18]. Positive attitudes have been associated with utilization of medical services for pain management, better engagement in pain reducing behaviours, better psychological and physical functioning [18]. A general belief is that medication is an effective cure for pain [17] and this moderates the relationship between pain severity and pain behaviours [19].

Expectations regarding the intensity, quality and duration of pain influence the subjective perception of pain. Negative expectation about recovery is associated with poorer recovery but causality cannot be implied [20]. Also health care providers' expectation can influence patients' expectation towards health outcomes and pain perception [20]. An important aspect of expectations is whether they are fulfilled or not. An unfulfilled expectation can lead to negative cognitions (e.g., if it hurts more than expected) and a fulfilled expectation can lead to reinforcement (e.g., if it hurts as much as expected). Given this, accurate expectations regarding experiencing pain, management, and recovery can have a positive impact on perception of pain.

Pain catastrophizing is characterized by the tendency to an exaggerated negative orientation towards a possible or an actual pain. Catastrophic thoughts are usually stated as helplessness thoughts (e.g., "There is nothing I can do to stop this pain"), magnification of the threatening potential of pain (e.g., "Feeling this pain is the worst thing that happened to me") and rumination (e.g., "I'm thinking about this pain constantly"). Pain catastrophizing is associated with the intensity of pain [21], emotional distress [22], pain medication use [23] disability [24] and lower physical and psychosocial functioning [25]. Patients' catastrophizing of pain was found to be associated not only with patients' depression but also with their partners' [26]. Pain catastrophizing was also associated with higher postoperative pain intensity, higher pain chronicity, and poorer quality of life after the surgery [27]. Given these findings, it should be emphasized that catastrophizing of pain is an extremely important factor in shaping and maintaining the experience of pain.

\section{EMOTIONAL FACTORS}

Pain has an important impact on patients' emotions. Emotional reaction to pain usually includes anxiety, fear, anger, guilt, frustration, and depression. How these emotions are controlled and managed by the patient (i.e., emotion regulation) have an impact on pain perception [8].

Pain related anxiety is associated with higher pain levels [28]. Anxiety is a predictor to the sensory dimension of the pain experience [29]. Anxiety is also a long term symptom in cancer survivors and impacts the quality of life [4]. 
Depression can be underdiagnosed and untreated in patients diagnosed with cancer [30]. Occurrence of depression is approximately one quarter of patient with advanced cancer [29]. Depression is more common in patients with increased pain severity. Also, pain intensity is positively associated with depression and the longer the pain is experienced the higher the risk for depression grows [31]. Even though pain and depression co-occur in patients with cancer, available evidence is not sufficient to imply a causal relationship [31]. Depression is a predictor of the affective dimension of the pain experience [29].

\section{COPING WITH CANCER RELATED PAIN}

Pain coping strategies or coping skills are cognitive (e.g., focusing away from the pain) or behavioural (e.g., muscle relaxation) techniques activated to reduce pain. Coping strategies can be adaptive (e.g., engaging in entertaining activities) or maladaptive (e.g., self-harming behaviours). Coping strategies are learned and evolve from the interaction of cognitive, emotional and behavioural systems [8]. It was found that children undergoing chemotherapy used a variety of coping strategies to deal with the pain and treatment side effects (e.g., understanding the need for chemotherapy, seeking pleasure in nourishment; engaging in entertaining activities and having fun, keeping the hope of cure alive, and finding support in religion) [32]. Studies investigating coping strategies in patients diagnosed with breast cancer found the most used coping strategies were positive self-statements (e.g., "I can handle this pain."), [33] relying on religion, acceptance of diagnosis, self-distraction from thinking about pain, positive reframing (e.g., "If I am in pain that just means the treatment is working.") and denial (e.g., "This is not happening to me."). Emotion focused strategies were found to have a significant influence on pain, while problem solving strategies did not had an impact on pain experience [34].

\section{MANAGEMENT OF CANCER RELATED PAIN}

Both pharmacologic and nonpharmacologic approaches to pain management are recommended. Psychosocial interventions are defined as approaches that are mainly comprised of cognitive-behavioural therapies, stress management interventions, relaxation training, educational interventions, and other experiential techniques. Psychosocial interventions can be provided in different settings such as individual/ couple/group interventions, or telephone/internetbased interventions. Psychosocial interventions used in cancer related pain can be divided into two subgroups: skill based and education based interventions. In skill based interventions the patient has an active role and learns how to manage pain through behavioural techniques, changes in interpretation of pain (e.g., catastrophizing, attention bias, etc.). In education based interventions patients acquire information about the disease, treatments, analgesic medications, and even effective communication regarding pain with their doctors. Education can be achieved through methods from in person sessions to informative videos or leaflets [35]. Psychological factors influence the experience of cancer related pain, but also have an impact on treatment for pain.

\section{THE IMPACT OF PSYCHOSOCIAL INTERVENTIONS IN REDUCING CANCER RELATED PAIN}

There is strong evidence for the inclusion of psychosocial interventions for pain in standard care of patients diagnosed with cancer. Meta-analysis is a commonly used statistical research method which allows the combination of results from different studies in order to better estimate the impact of an intervention. The effect size of an intervention can be seen as an indicator of the amount of change provided by the intervention. Usually, the value of effect size coefficients can be divided into three levels: small, medium, large effect sizes.

Eight published meta-analyses evaluated the impact of psychosocial interventions on pain associated with cancer [1, 36-42]. These metaanalyses consistently reported medium effect sizes, one meta-analysis reporting large effect size that supports psychosocial interventions in reducing pain in patients diagnosed with cancer.

In two meta-analyses that focused only on education based interventions, one reported a large effect size (WMD =-1.1) [40] and the other a small effect size $(\mathrm{SMD}=-0.1)$ [41]. Two meta-analyses that focused exclusively on skill based interventions found medium effect sizes. The impact of relaxation training on pain had an effect size of $d=0.43$, but results are based only on three studies [37]. The impact of CBT techniques on pain also found a medium effect size $(d=0.49)$ [39], but results are based only on patients diagnosed with breast cancer. 
In other meta-analyses it was broadened the search on the entire spectrum of psychosocial interventions. When only studies with breast cancer patients were analysed it was found that psychosocial interventions have a small effect size $(g=0.37)$ [42]. When the analysis was made on the two subgroups of interventions authors found that education based interventions had a larger effect size $(g=0.64)$ than relaxation based interventions $(\mathrm{g}=0.30)$ or supportive group therapy $(\mathrm{g}=0.17)$. The effect size of psychosocial interventions in studies with mixed types of cancer was small to medium $(\mathrm{g}=0.34)$. In this case, skill based interventions had a slightly larger effect size $(g=0.45)$ than education based interventions $(\mathrm{g}=0.29)$, but the difference was not statistically significant [1]. A meta-analysis focused on psycho educational interventions and found a medium effect size (SMD $=0.43$ ) but when only relaxation based interventions were included in the analysis, a large effect size was found $(\mathrm{SMD}=0.9)$ [36]. Another meta-analysis found that psycho educational interventions had a medium effect size $(\mathrm{SMD}=0.41)$. When subgroups of interventions were analysed, the largest effect size was found for relaxation-promoting cognitive-behavioural interventions $(\mathrm{SMD}=0.65)$. Other subgroups of intervention (e.g., educational, supportive counselling) showed small to moderate effect sizes [38].

Meta-analyses are a valuable method to evaluate and compare the effect of various interventions on the same outcomes. The results of meta-analyses are conditioned by the amount and the quality of studies. Studies can be grouped in different categories in order to analyse the impact of different variables on the outcome of the interventions. Studies in which the intervention protocol was monitored had a statistically significant increase in effect $(\mathrm{g}=0.52)$ than those which did not monitor the intervention protocol $(\mathrm{g}=0.29)$ [1]. This finding suggests that if measures are taken to assure a correct implementation of procedure the impact of psychosocial interventions in reducing pain is significantly higher.

\section{CONCLUSIONS}

In this paper psychological factors involved in experience of cancer related pain (i.e., attentional, cognitive, affective and coping strategies) and evidence-based supported psychosocial interventions to reduce pain associated with cancer are briefly presented.

In line with biopsychosocial model of pain, psychological factors and psychosocial interventions and patient empowerment aspects play a central part in effective management of cancer related pain. Patient empowerment is defined as "a process to help people gain control, which includes people taking the initiative, solving problems and making decisions" [43]. A conceptual model to empower patients affected by cancer related pain was proposed [44], and equally emphasizes the role of patient as partner in decision making with access to relevant resources, and the role of healthcare professional to provide access to resources in order to facilitate patient's active coping and self-efficacy.

Extensive empirical research shows that psychosocial interventions are effective in reducing pain associated with cancer. These findings are consonant with the recommendation of American Pain Society for a multimodal approach in the management of cancer-related pain [35]. For an efficient management of cancer related pain we recommend health professionals to be aware of psychological factors role in emergence and maintenance of pain, and the impact of psychosocial interventions in reducing cancer related pain.

Conflict of Interest disclosure: The authors declare that there are not conflicts of interest.

Articolul prezent are ca scop prezentarea pe scurt a factorilor psihologici implicați în durerea asociată cu cancerul şi intervențiile psihosociale dovedite a fi eficiente în reducerea durerii. Durerea asociată cu cancerul este o experiență complexă şi cea mai integratoare abordare a acesteia este modelul biopsihosocial. Este dovedit faptul că durerea cronică este mai puternic legată de factorii psihologici decât de factorii asociați cu tratamentul sau cu boala. Factorii psihologici care influențează experiența durerii pot fi grupați în următoarele categorii: conştientizarea durerii (factorul atențional), evaluarea durerii (factori cognitivi), emoții şi comportamente (strategii de coping) asociate durerii. Intervențiile 
psihosociale (intervenții bazate pe formarea de abilități de management al durerii sau intervenții educaționale) au dovezi empirice puternice care arată că sunt eficiente în reducerea durerii asociată cu cancerul.

Correspondence to: Adriana Băban PhD, Professor of Health Psychology

Department of Psychology, "Babeş-Bolyai” University, 37 Republicii St., 400015,

Cluj-Napoca, Romania, Tel/Fax: +40.264 .590 .967$

E-mail: adrianababan@psychology.ro,

Web: www.ubbcluj.ro, www.psiedu.ubbcluj.ro

\section{REFERENCES}

1. GORIN SS., KREBS P., BADR H., JANKE EA., JIM HSL., SPRING B., et al. Meta-analysis of psychosocial interventions to reduce pain in patients with cancer. J Clin Oncol. 2012; 30(5):539-47.

2. EVERDINGEN MVDB-V., RIJKE JD., KESSELS A., SCHOUTEN H., KLEEF MV., PATIJN J. Prevalence of pain in patients with cancer: a systematic review of the past 40 years. Ann Oncol. 2007; 18(9):1437-49.

3. GUTGSELL T., WALSH D., ZHUKOVSKY DS., GONZALES F., LAGMAN R. A prospective study of the pathophysiology and clinical characteristics of pain in a palliative medicine population. Am J Hosp Palliat Care. 2003; 20(2):140-8.

4. HARRINGTON CB., HANSEN JA., MOSKOWITZ M., TODD BL., FEUERSTEIN M. It's not over when it's over: long-term symptoms in cancer survivors - A systematic review. Int J Psychiat Med. 2010; 40(2):163-81.

5. NOVY DM., AIGNER CJ. The biopsychosocial model in cancer pain. Curr Opin Support Palliat Care. 2014; 8(2):117-23.

6. ZAZA C., BAINE N. Cancer pain and psychosocial factors. J Pain Symptom Manag. 2002; 24(5):526-42.

7. SYRJALA KL., JENSEN MP., MENDOZA ME., YI JC., FISHER HM., KEEFE FJ. Psychological and behavioral approaches to cancer pain management. J Clin Oncol. 2014; 32(16):1703-11.

8. LINTON SJ., SHAW WS. Impact of psychological factors in the experience of pain. Phys Ther. 2011; 91(5):700-11.

9. ECCLESTON C., CROMBEZ G. Pain demands attention: A cognitive-affective model of the interruptive function of pain. Psychol Bull. 1999; 125(3):356-66.

10. VILLEMURE C., BUSHNELL CM. Cognitive modulation of pain: how do attention and emotion influence pain processing? Pain. 2002; 95(3):195-9.

11. SHARPE L., IANIELLO M., DEAR BF., PERRY KN., REFSHAUGE K., NICHOLAS MK. Is there a potential role for attention bias modification in pain patients? Results of 2 randomised, controlled trials. Pain. 2012; 153(3):722-31.

12. DIMOVA V., HORN C., PARTHUM A., KUNZ M., SCHÖFER D., CARBON R., et al. Does severe acute pain provoke lasting changes in attentional and emotional mechanisms of pain-related processing? A longitudinal study. Pain. 2013; 154(12):2737-44.

13. LOW LA. The impact of pain upon cognition: What have rodent studies told us? Pain. 2013; 154(12):2603-5.

14. KHATIBI A., SHARPE L., JAFARI H., GHOLAMI S., DEHGHANI M. Interpretation biases in chronic pain patients: an incidental learning task. Eur J Pain. 2014; 19(8):1139-47.

15. JENSEN MP., ROMANO JM., TURNER JA., GOOD AB., WALD LH. Patient beliefs predict patient functioning: further support for a cognitive-behavioural model of chronic pain. Pain. 1999; 81(1):95-104.

16. DEGOOD DE., SHUTTY MS. Assessment of pain beliefs, coping and self-efficacy. In: Turk DC., Melzack R. Handbook of pain assessment. Guildford, New York, 1992.

17. TAIT RC., CHIBNALL JT. Development of a brief version of the survey of pain attitudes. Pain. 1997; 70(2):229-35.

18. JENSEN MP., KAROLY P. Pain-specific beliefs, perceived symptom severity, and adjustment to chronic pain. Clin J Pain. 1992; 8(2): $123-30$.

19. SHEN MJ., REDD WH., WINKEL G., BADR H. Associations among pain, pain attitudes, and pain behaviors in patients with metastatic breast cancer. J Behav Med. 2013; 37(4):595-606.

20. PINCUS T., MCCRACKEN LM. Psychological factors and treatment opportunities in low back pain. Best Pract Res Clin Rheumatol. 2013; 27(5):625-35.

21. SULLIVAN MJL., BISHOP SR., PIVIK J. The pain catastrophizing scale: Development and validation. Psychol Assessment. 1995; 7(4):524-32.

22. SULLIVAN MJ., RODGERS WM., KIRSCH I. Catastrophizing, depression and expectancies for pain and emotional distress. Pain. 2001; 91(1):147-54.

23. BEDARD GBV., REID GJ., MCGRATH PJ., CHAMBERS CT. Coping and self-medication in a community sample of junior high school students. Pain Res Manag. 1997; 2(3):151-6.

24. KEEFE FJ., LEFEBVRE JC., EGERT JR., AFFLECK G., SULLIVAN MJ., CALDWELL DS. The relationship of gender to pain, pain behavior, and disability in osteoarthritis patients: the role of catastrophizing. Pain. 2000; 87(3):325-34.

25. CHO S., KIM H-Y., LEE J-H. Validation of the Korean version of the pain catastrophizing scale in patients with chronic noncancer pain. Qual Life Res. 2012; 22(7):1767-72.

26. BADR H., SHEN MJ. Pain catastrophizing, pain intensity, and dyadic adjustment influence patient and partner depression in metastatic breast cancer. Clin J Pain. 2014; 30(11):923-33.

27. KHAN RS., AHMED K., BLAKEWAY E., SKAPINAKIS P., NIHOYANNOPOULOS L., MACLEOD K., et al. Catastrophizing: a predictive factor for postoperative pain. Am J Surg. 2011; 201(1):122-31. 
28. GALLOWAY SK., BAKER M., GIGLIO P., CHIN S., MADAN A., MALCOLM R., et al. Depression and anxiety symptoms relate to distinct components of pain experience among patients with breast cancer. Pain Res Treat. 2012; 2012:1-4.

29. LLOYD-WILliAMS M., DENNIS M., TAYLOR F. A prospective study to determine the association between physical symptoms and depression in patients with advanced cancer. Palliative Med. 2004; 18(6):558-63.

30. CAPLETTE-GINGRAS A., SAVARD J. Depression in women with metastatic breast cancer: A review of the literature. Palliat Support Care. 2008; 6(04):377.

31. LAIRD BJ., BOYD AC., COLVIN LA., FALLON MT. Are cancer pain and depression interdependent? A systematic review. Psycho-Oncol. 2009; 18(5):459-64.

32. SPOSITO AMP., SILVA-RODRIGUES FM., SPARAPANI VDC., PFEIFER LI., LIMA RAGD., NASCIMENTO LC. Coping strategies used by hospitalized children with cancer undergoing chemotherapy. J Nurs Scholarsh. 2015; 47(2):143-51.

33. CZERW A., RELIGIONI U., DEPTALA A. Assessment of pain, acceptance of illness, adjustment to life with cancer and coping strategies in breast cancer patients. Breast Cancer. 2015; 23(4):654-61.

34. KHALILI N., FARAJZADEGAN Z., MOKARIAN F., BAHRAMI F. Coping strategies, quality of life and pain in women with breast cancer. Iran J Nurs Midwifery Res. 2013; 18(2), 105.

35. GORDON DB., DAHL JL., MIASKOWSKI C., MCCARBERG B., TODD KH., PAICE JA., et al. American pain society recommendations for improving the quality of acute and cancer pain management. Arch Intern Med. 2005; 165(14):1574.

36. DEVINE EC., WESTLAKE SK. The effects of psychoeducational care provided to adults with cancer: meta-analysis of 116 studies. Oncol Nurs Forum. 1995; 22(9):1369-81.

37. LUEBBERT K., DAHME B., HASENBRING M. The effectiveness of relaxation training in reducing treatment-related symptoms and improving emotional adjustment in acute non-surgical cancer treatment: a meta-analytical review. Psycho-Oncol. 2001; 10(6):490-502.

38. DEVINE EC. Meta-analysis of the effect of psychoeducational interventions on pain in adults with cancer. Oncol Nurs Forum. 2003; 30(1):75-89.

39. TATROW K., MONTGOMERY GH. Cognitive behavioral therapy techniques for distress and pain in breast cancer patients: A meta-analysis. J Behav Med. 2006; 29(1):17-27.

40. BENNETT MI., BAGNALL A-M., CLOSS JS. How effective are patient-based educational interventions in the management of cancer pain? Systematic review and meta-analysis. Pain. 2009; 143(3):192-9.

41. JHO HJ., MYUNG S-K., CHANG Y-J., KIM D-H., KO DH. Efficacy of pain education in cancer patients. Supportive Care in Cancer. 2013; 21(7):1963-71.

42. JOHANNSEN M., FARVER I., BECK N., ZACHARIAE R. The efficacy of psychosocial intervention for pain in breast cancer patients and survivors: a systematic review and meta-analysis. Breast Cancer Res Treat. 2013; 138(3):675-90.

43. European Network on Patient Empowerment (ENOPE). Patient empowerment - who empowers whom? The Lancet. 2012; 379(9827): 1677.

44. BOVELDT NT., VERNOOIJ-DASSEN M., LEPPINK I., SAMWEL H., VISSERS K., ENGELS Y. Patient empowerment in cancer pain management: an integrative literature review. Psycho-Oncol. 2014; 23(11):1203-11.

Received 13 December, 2016 